\title{
Honey ameliorates ampiclox-induced testicular damage in male Wistar rats Rattus norvegicus (Berkenhout, 1769) (Rodentia: Muridae)
}

\section{Eweoya Olugbenga Olawale ${ }^{1 * *}$, Emmanuel Betty ${ }^{2}$ and Ajayi Abayomi ${ }^{3}$}

${ }^{1}$ Department of Anatomical Sciences, College of Health Sciences, University of Abuja, Nigeria.*E-mail: ewegbenga@yahoo.com.

${ }^{2}$ Department of Anatomy, College of Health Sciences, Bingham University, Karu, Nigeria.

${ }^{3}$ Department of Anatomy, Faculty of Basic Medical Sciences, College of Health Sciences, Kogi State University Anyigba, PMB 1008, Anyigba, Nigeria.

\begin{abstract}
In an experiment to determine the effect of honey on ampiclox-induced testicular damage in rats, twenty (20) adult Wistar rats Rattus norvegicus (Berkenhout, 1769) (Rodentia: Muridae) weighing 150-250 g were divided into four groups (A-D) of five rats each. Group A (control) was administered with $0.5 \mathrm{~mL}$ distilled water, group B was given freshly prepared honey orally by gavage daily at a dose of $1.2 \mathrm{~g} / \mathrm{kg}$ body weight (b.wt), group C received ampiclox (50 mg/kg b.wt) daily while group D received ampiclox (50 mg/kg b.wt) and honey (1.2 g/kg b.wt) for a duration of 14 days. Findings indicate that honey significantly reduced ampiclox-induced damage on the testicular histology. It also improved the serum testosterone level and sperm parameters. The study suggests that honey has a protective effect against testicular damage caused by ampiclox.
\end{abstract}

Keywords: Male infertility; Ampiclox; Sperm; Honey; Wistar rats.
Received

May 5, 2016

Accepted May 30, 2016

Released June 30, 2016
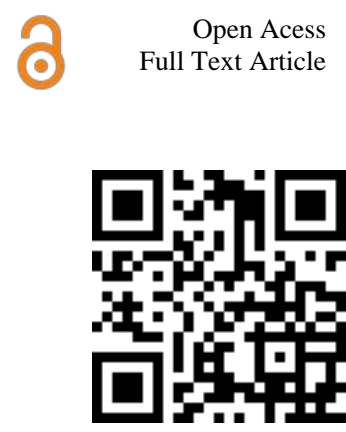

ORCIID

(ㄱ) 0000-0002-9528-3407

Eweoya Olugbenga

Olawale

두 0000-0003-0884-3769

Emmanuel Betty

(ㄱ) 0000-0001-8181-7407

Ajayi Abayomi

\section{Introduction}

Infertility is defined as the involuntary absence of conception in a sexually active, non-contraceptive couple after a general period of at least one year (Shittu et al., 2005). In primary infertility, there is an absence of product of conception and in secondary infertility there is the inability to obtain any further conception after a previous issue. Humans are showing declining fertility, which affects about 15\% to $18 \%$ couples attempting pregnancy (Raji et al., 2006). Although women have been 
thought to be the main cause of childless partners in the past, recent investigations showed that the male and female can equally be responsible, including environmental factors, with male factor identified in about half of the cases.

The male reproductive system is highly sensitive, and which attributes to the rising prevalence of male factor infertility worldwide. Anatomical, genetic, endocrinological and immunological problems can all cause or contribute to male infertility. These problems could result from nutrition, lifestyle such as cigarette smoking and drinking and exposure to environmental toxicants (Shika and Wang, 2008). Drugs and chemicals being part of the environment have been found to pose adverse effect on male reproductive capability (Raji et al., 2006). Drug such as the antibiotic therapy has also been shown to significantly affect spermatogenesis and seminal parameters in both human and animal models (Olayemi, 2010).

Antibiotics in the penicillin group (penicillin-G, ampicillin and dicloxacillin) have been implicated in causing spermatogenic arrest (Olayemi, 2010). Experimental Studies has shown that ampicillin and cloxacillin cause significant reduction in the weights of testes, epididymis, seminal vesicle and prostate glands (Raji et al., 2006). Also a significant decrease in sperm count, motility, viability and morphologically abnormal spermatozoa in male rats.

Over the years, curative measures have been applied to reduce infertility. These measures include the use of herbs, vitamin supplements, drugs and medical procedures (Carangelo, 2013). Honey has been used as both as a natural sweetener and healing agent. But in recent years scientific support is beginning to emerge confirming the beneficial effects of honey on certain medical and surgical conditions such as male infertility (Igbokwe et al., 2013). Honey as a natural product of bees formed from nectar collected from flowering vegetation has been found to have spermato-protective effect (Mahaneem et al., 2011). It is also a high nutrient source and contains sugars such as glucose and fructose, enzymes such as catalase and gluthanione reductase, trace elements such as iron, copper, zinc, calcium, vitamins such as vitamin $\mathrm{A}, \mathrm{C}$ and $\mathrm{E}$ as well as some flavonoids and phenolic acids (Estevinho et al., 2008; Syazana et al., 2011).

Previous work done on honey showed that compared to the standard antifertility drug Mantrix, honey enhanced sperm quality by improving the sperm parameters of sperm count, sperm motility, sperm viability and sperm morphology (Adekunle et al., 2010; Igbokwe et al., 2013). It has also been shown that honey significantly reduced the toxic effect of cigarette smoke on the testicular structure (Mahaneem et al., 2011).

The rising prevalence of infertility resulting from decreased human sperm quality due to continuous exposure and intake of drugs and chemicals has been of concern over the years. Hence we aim to investigate the effect of honey on sperm parameters and testosterone level as well as on the histology of ampiclox-induced testicular damage in rats.

\section{Materials and methods}

\section{Animal source and handling}

20 adult male Wistar rats Rattus norvegicus (Berkenhout, 1769) (Rodentia: Muridae) weighing $150-250 \mathrm{~g}$ were procured from the National Institute for Veterinary Research, Plateau State, Nigeria. The rats were housed in wired mesh cages and kept in the animal house. They were fed with vital feed (Growers mesh) and water ad libitum and allowed to acclimatize for a period of two weeks.

\section{Honey and ampliclox}

Beecham ampiclox was obtained from Betty Pharmaceutical Store at Gwarimpa, Abuja, Nigeria, while pure natural honey was obtained from Kwoi Market, Kaduna State, Nigeria.

\section{Experimental design}

The 20 rats were randomly divided into four groups of five rats per wire mesh cage and the groups were treated as follows, Group A (control): Administered with 
$0.5 \mathrm{~mL}$ distilled water. Group B: Administered freshly prepared honey orally by gavage daily at a dose of $1.2 \mathrm{~g} / \mathrm{kg}$ body weight (using distilled water as a vehicle). This dose was worked out relative to the local human consumption of honey which is $0.2 \mathrm{~g} / \mathrm{kg}$ body weight daily. Group C: Administered with (50 mg/kg b.wt) daily. Group D: Administered with ampiclox (50 $\mathrm{mg} / \mathrm{kg}$ b.wt) and honey (1.2 g/kg b.wt). The duration of the study was 14 days, at the end of which animals were sacrificed, and blood, semen and tissues collected for analysis.

\section{Animal sacrifice}

$24 \mathrm{~h}$ after the last dosing, blood was withdrawn from the animals for serum collection and testosterone assay and then the animals were sacrificed by cervical dislocation and the testis and epididymis were excised following abdominal incision.

\section{Reproductive organ weight}

The testis and the epididymis were excised from the rats, cleared from adherent fat and weighed immediately to the nearest milligram and then preserved for histological analysis.

\section{Semen collection and analysis}

The caudal epididymis were dissected and minced in $1 \mathrm{~mL}$ of $(0.9 \%)$ normal saline and the sperm count was done using the heamatocytometer counting chamber of the Neubauer type. Semen from the cauda epididymis was collected onto a pre warmed microscope glass slide for motility and viability studies.

\section{Serum collection and testosterone assay}

$24 \mathrm{~h}$ after dosage blood samples were collected through the retro orbital sinus into sterile bottles and was then centrifuged at 10,000 rpm for $15 \mathrm{~min}$. The serum was separated from plasma and stored at $-20^{\circ} \mathrm{C}$ for testosterone assay.

\section{Histological preparations}

The tissues of the testis and epididymis were fixed in $10 \%$ formalsaline. The organs were cut in slices of about $0.5 \mathrm{~cm}$ thick, dehydrated in graded series of alcohol from $70 \%$ to $90 \%$ and then cleared in xylene for different durations. The tissues were then transferred into two changes of molten paraffin wax for $1 \mathrm{~h}$ each in an oven at $65^{\circ} \mathrm{C}$ for infiltration. They were subsequently embedded and serial sections cut using rotary microtome at 5 $\mu \mathrm{m}$. The tissues were transferred onto albumenized slides and allowed to dry on hot plates for $2 \mathrm{~min}$. The slides were dewaxed with xylene and passed through two changes of absolute alcohol, $70 \%$ alcohol, $50 \%$ alcohol and then to water for $5 \mathrm{~min}$. The slides were then stained with Haematoxylin and Eosin stains.

\section{Statistical analysis}

All the data were statistical evaluated using ANOVA with SPSS 17.0 software (SPSS Inc, Chicago, USA) and the data were represented as Mean \pm standard error of mean (SEM). Differences were considered to be statistically significant at $\mathrm{P}<0.05$.

\section{Results and discussion}

Results showed that ampiclox treatment has no significant effect on the body weight of the treated group as continuous normal growth of the rats was observed from the beginning to the end of the experiment (Figure 1).

Analysis of testicular and epididymal weight changes at the end of the experiment (Table 1) shows that the honey treated group (group B) experienced an increase in relative testicular and epididymal weight which was not significantly different from control $(p<0.05)$. However, there was a significant decrease in the relative epididymal weight $(p<0.05)$ in the ampiclox treated group (group C) as compared with the control. In the ampiclox and honey treated group (group D), there was an increase in the relative testicular and epididymal weight although was not significantly different from control $(\mathrm{p}<0.05)$. 


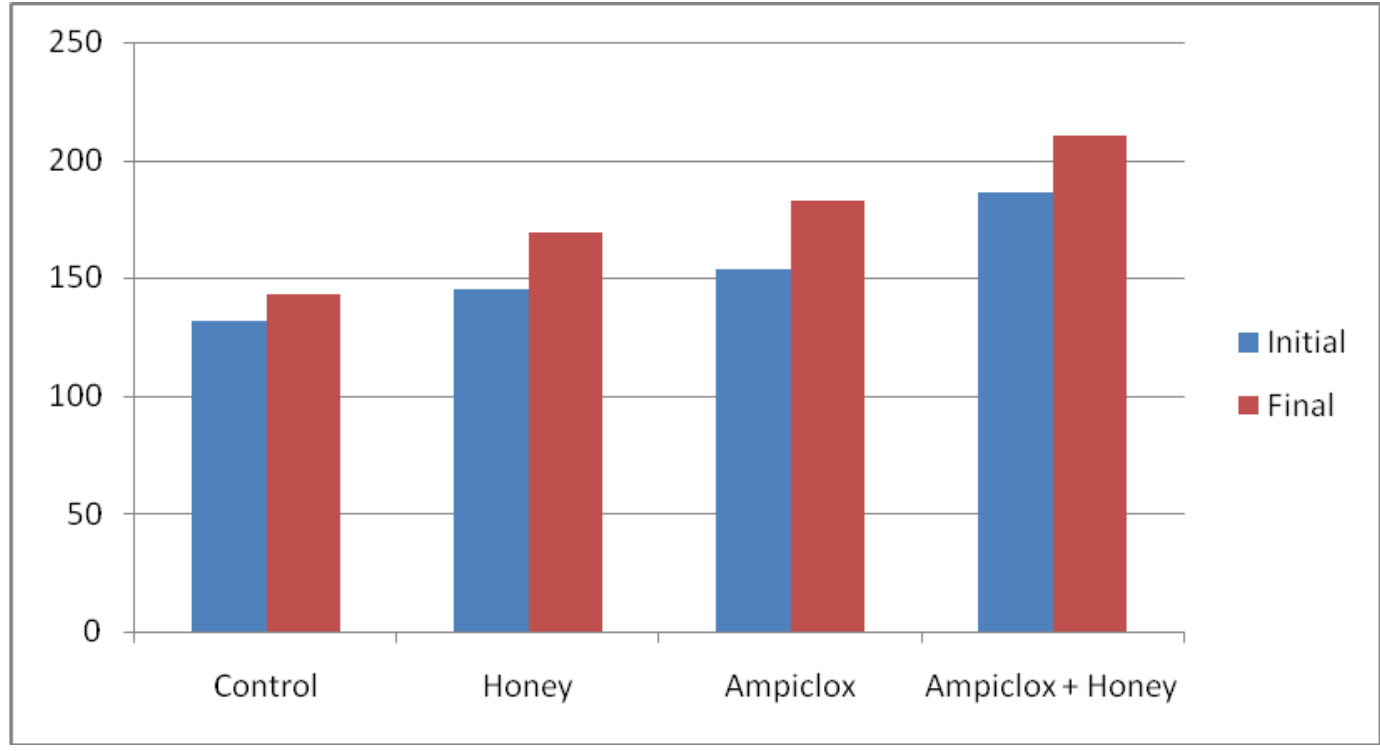

Figure 1. Graphical representation of initial and final body weight (g) of experimental rats before and after experiment.

Table 1. Effect of honey and ampiclox on testicular and epididymal weight.

\begin{tabular}{|l|c|c|}
\hline Group & Testicular weight & Epididymal weight \\
\hline A (Control) & $1.16 \pm 0.02$ & $0.13 \pm 0.01$ \\
\hline B (Honey only) & $1.24 \pm 0.05$ & $0.14 \pm 0.01$ \\
\hline C (Ampiclox only) & $0.82 \pm 0.02^{*}$ & $0.02 \pm 0.02^{*}$ \\
\hline D (Ampiclox + honey) & $1.14 \pm 0.03$ & $0.16 \pm 0.03$ \\
\hline
\end{tabular}

Values were expressed as Mean \pm SEM. $(*)$ Mean statistically different from control at $\mathrm{P}<0.05$ (ANOVA).

In the honey treated rats (group B), sperm parameters and serum reproductive hormonal levels were not significantly different from control, with normal testicular tissue and increasing spermatogenetic activities compared to the control. This is consistent with previous work (Abdul-Ghahi et al., 2008; Mahaneem et al., 2011; Syanzana et al., 2011).

Accompanying the reduction in epdidymal weight in the ampiclox treated rats was corresponding significant decrease in sperm count, motility and viability (Table 2). Moderate degenerative changes in the testicular tissues, and less to absence of Leydig cells in the interstitial space compared to the control group was also observed. This corresponds with previous findings on the histomorphometric effect of antibiotics on the male reproductive system (Awobajo et al., 2010; Raji et al., 2006). It has been established that changes in the either absolute or relative weight of an organ following administration of a drug is an indicator of the toxic effect of the drug on the organ (Simmons et al., 1995). Thus, the decrease in the relative weight of the epididymis in this study indicates the toxic effect of the ampiclox on the organ.

A significant decrease in serum testosterone level in the ampiclox-treated rats, as observed in this study (Table 3 ) is in agreement with earlier reports showing a decrease in serum testosterone level by some antibiotics including cloxacillin and ampicillin (Awobajo et al., 2006; Raji et al., 2006). There was also a significant decrease in the serum level of Follicle Stimulating Hormone and Luteinizing Hormone, which indicates that ampiclox might have an effect on the secretion of hormones from the anterior pituitary gland. 
Table 2. Effect of honey and ampiclox treatment on sperm parameters.

\begin{tabular}{|c|c|c|c|}
\hline Group & $\begin{array}{c}\text { Sperm count } \\
\left(\times 10^{6} / \mathrm{mL}\right)\end{array}$ & Sperm motility (\%) & Sperm vaibility \\
\hline A (Control) & $106.4+2.48$ & $84.0+7.92$ & $79.6 \pm 10.18$ \\
\hline B (Honey only) & $103.8+4.00$ & $93.8+1.63$ & $96.4+1.72$ \\
\hline C (Ampiclox only) & $62.2 \pm 7.17^{*}$ & $40.4 \pm 11.00 *$ & $41.0 \pm 11.97 *$ \\
\hline D (Ampiclox + honey) & $100.4 \pm 4.95$ & $87.80+6.10$ & $78.8+8.72$ \\
\hline
\end{tabular}

Values were expressed as Mean \pm SEM. (*) Mean significantly different from control (Group A) at $\mathrm{P}<0.05$ (ANOVA).

Table 3. Effect of honey and ampiclox treatments on reproductive hormones level.

\begin{tabular}{|l|c|c|c|}
\hline Group & $\begin{array}{c}\text { Testosterone } \\
(\mathbf{n g} / \mathbf{m L})\end{array}$ & FSH (mIU/mL) & LH (mIU/mL) \\
\hline A (Control) & $1.26 \pm 0.14$ & $0.68 \pm 0.10$ & $0.24 \pm 0.067$ \\
\hline B (Honey only) & $1.14 \pm 0.07$ & $0.65 \pm 0.07$ & $0.25 \pm 0.048$ \\
\hline C (Ampiclox only) & $0.21 \pm 0.07^{*}$ & $0.06 \pm 0.03^{*}$ & $0.02 \pm 0.01^{*}$ \\
\hline D (Ampiclox + Honey) & $0.67 \pm 0.20$ & $0.04 \pm 0.00^{*}$ & $0.01 \pm 0.00^{*}$ \\
\hline
\end{tabular}

Values were expressed as Mean \pm SEM. $(*)$ Mean significantly different from control (Group A) at $\mathrm{P}<0.05$ (ANOVA).

The observed distortion in the testicular tissue in the ampiclox treated rats (Figure 2) is evidence of its interference with the highly sensitive testicular microenvironment. Also, the sparse to absence of Leydig cells in the interstitial space explains the significant decrease in serum testosterone level since Leydig cells are responsible for the production of testosterone. Decreased spermatogenic activities and delayed spermiation is characteristically seen when serum Follicle Stimulating hormonal level is low and testosterone production is impaired. This underlies the significant decrease in sperm count, motility and viability observed in the ampiclox treated rats in this study, since the hormones are required for spermatogenesis, growth and maintenance of male reproductive organ.

In the ampiclox and honey treated group, there was a significant restoration in serum testosterone level towards the control although there was a significant decrease in the serum levels of Follicle Stimulating Hormone and Luteinizing Hormone. The relative testicular and epididymal weights in this group were not significantly different from the control. Also, parameters such as sperm count, sperm motility and sperm viability, and testicular tissue ultrastructure were not significantly different from the control. Abdul-Ghani et al. (2008) reported that honey increased the activities of testicular marker enzymes for spermatogenesis such as sorbitol dehydrogenase by $31 \%$. This enzyme is involved in carbohydrate metabolism converting sorbitol, the sugar alcohol form of glucose, to fructose (El-Kabbani et al., 2004). Since fructose is a component of honey and an important marker in seminal fluid, honey enhances sperm quality in that it provides nutrients and energy as it metabolizes through the glycolytic pathway in the testes to make ATP for the sperm and the perfect alkaline medium for sperms to maintain their viability, thus enhancing their motility.

The significant increase in serum testosterone level towards the control and significant decrease in serum Follicle Stimulating Hormone and Luteinizing Hormone levels in the ampiclox and honey treated group indicates that honey has no significant effect on the serum levels of Follicle Stimulating Hormone and Luteinizing Hormone but has a significant effect on serum testosterone level. Honey as a high nutrient source acts locally in the 


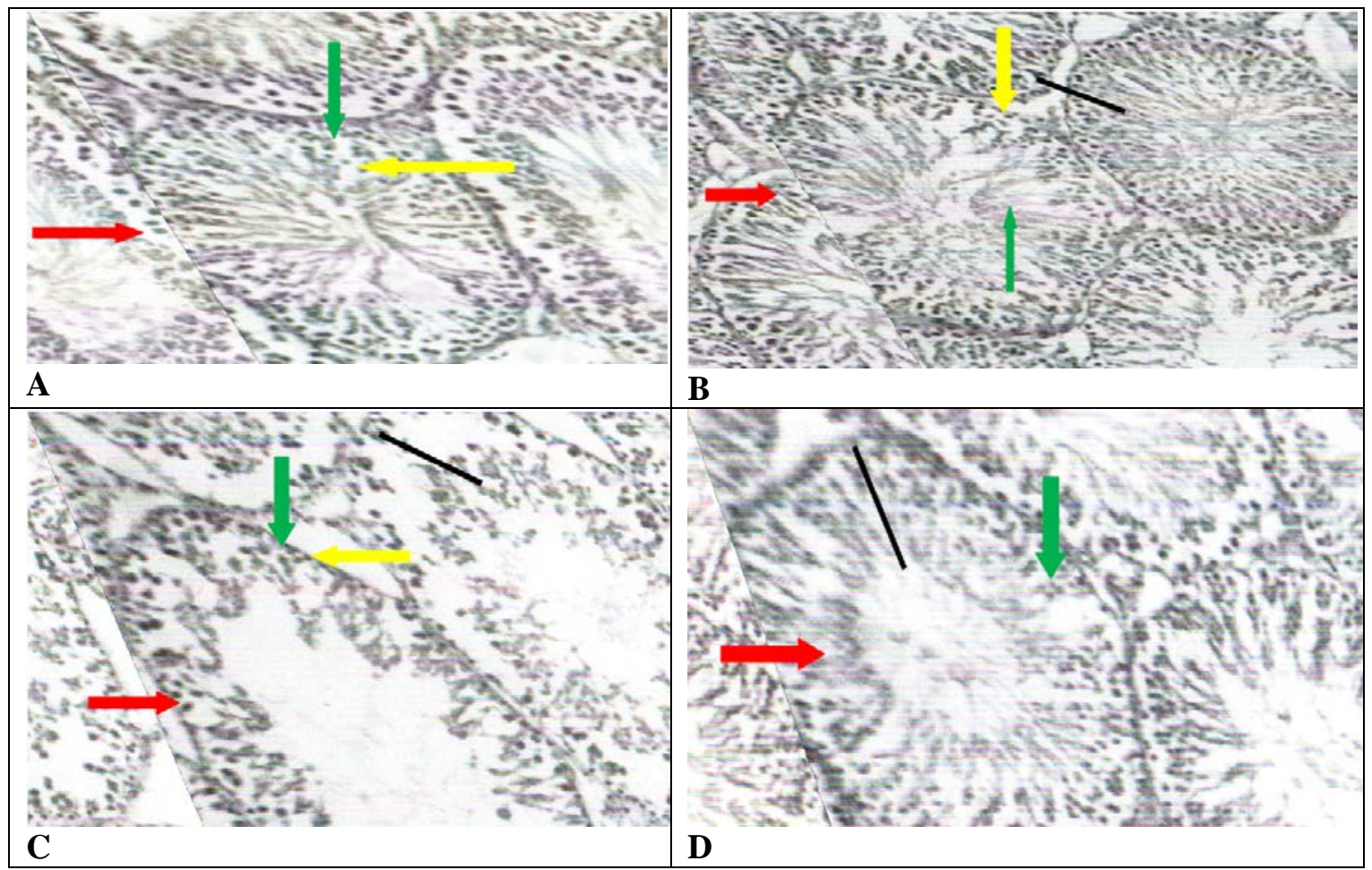

Figure 2. Effect of honey and Ampiclox treatments on histology of the testis. (A) Photomicrograph of the testis of Wistar rat of group A (control) showing normal seminiferous tubules, normal germinal epithelium (yellow arrow), normal and filled up lumen with presence of spermatozoa(red arrow). The interstitial spaces and leydig cells appear normal surrounded by connective tissue(green arrow). H\&Ex100. (B) Photomicrograph of the testis of Wistar rat of honey (group B) showing normal seminiferous tubules with increasing spermatogenic activities (Black arrow), normal germinal epithelium (yellow arrow), normal and filled up lumen with presence of spermatozoa (red arrow). The interstitial spaces and leydig cells appear normal surrounded by connective tissue (green arrow). H\&E x100. (C) Photomicrograph of the testis of Wistar rat of Ampiclox group (group C) showing slight seminiferous tubular degeneration (Black arrow), thinning of the germinal epithelium (yellow arrow), empty lumen with absence of spermatozoa (red arrow) and exaggerated interstitial spaces with loss of Leydig cells (green arrow). H\&E x100. (D) Photomicrograph of the testis of Wistar rat of Ampiclox and honey treated group (group D) showing improved seminiferous tubular activities (Black arrow), normal germinal epithelium(yellow arrow),lumen appear normal with presence of spermatozoa(red arrow). The interstitial space with Leydig cells appear normal (green arrow). H\&E x100.

testis by restoring or improving the functions of Leydig cells, which are responsible for the production of testosterone (Mahaneem et al., 2011), since testosterone is essential for spermatogenesis. This underlies the improved spermatogenic activities and close to normal testicular tissue observed in the ampiclox and honey treated rats in this study. The testis primarily has two functions which are gametogenic and hormonal functions. Both functions are however influenced by the gonadotrophic hormones, Follicle stimulating hormone and Luteinizing Hormone, produced by the anterior pituitary gland and the hypothalamus. Luteinizing hormone stimulates the Leydig cells in the interstitium of the testes to secrete testosterone, and Follicle stimulating hormone acts directly on the sertoli cells to promote spermatogenesis.

Honey contains various nutritional constituents and has been found to have protective properties and fertility boosting abilities (Adekunle et al., 2010). Hence possible beneficial role of honey supplementation, either alone or in 
combination with other drugs, in protecting or treating male reproductive health problems and the oxidative effects of ampiclox on the testicular tissue and the possible use of honey to ameliorate such effects is suggested to be further studied. The rising prevalence of infertility resulting from decreased human sperm quality due to continuous exposure and intake of drugs and chemicals has been of concern over the years, making infertility curative measures, treatments and drugs not cost effective and quite expensive.

\section{Conclusion}

The findings in this study demonstrated that honey significantly reduced the damage induced by ampiclox on the testicular histology. It also improved the serum testosterone level and sperm parameters. This study suggests that honey has a protective effect against testicular damage caused by ampiclox hence, the effect of antibiotics such as ampiclox on sperm functions should be evaluated when treating male patients.

\section{Conflict of interest statement}

Authors declare that they have no conflict of interests.

\section{References}

Abdul-Ghahi, A. S.; Dabdoub, N.; Muhammed, R.; Abdul-Ghahi, R.; Qazzaz, M. Effect of Palestinian honey on spermatogenesis in rats. Journal of Medical Food, v. 11, no. 4, p. 799802, 2008. http://dx.doi.org/10.1089/jmf.2008.0085

Adekunle, A. S.; Adebio, J. A.; Oyewopo, O. Journal of Pharmaceutical and Biomedical Sciences, v. 3, no. 2, p. 2230-7885, 2010. $<$ http://www.jpbms.info/index.php?option=com _docman\&task=doc_download\&gid=77\&Itemi $\mathrm{d}=41>$. Accessed in: Apr. 23, 2016.

Awobajo, F. O., Raji, Y.; Akinloye, A. K. Histomorphometric changes in the testis and epididymis of Wistar strain albino rats following fourteen days oral administration of therapeutic doses of some antibiotics. Int. J. Morphol., v. 28, no. 4, p. 1281-1287, 2010.
http://dx.doi.org/10.4067/S071795022010000400047

Awobajo, F. O.; Raji, Y.; Olatunji-Bello, I. I.; Kunle-Alabi, F. T.; Adesanya, A. O.; Awobajo, T. O. Fourteen days oral administration of therapeutic dosage of some antibiotics reduced serum testosterone in male rats. Niger. J. Health Biomed. Sci., v. 5, p. 17-20, 2006. http://dx.doi.org/10.4314/njhbs.v5i1.11567

Carangelo, L. Infertility cures (instead of adoption). Palm Desert: Access Press, 2013. Available from: $<$ http://www.barnesandnoble.com/w/infertilitycures-lori-carangelo/1113899269>. Accessed in: Apr. 23, 2016.

El-Kabbani, O.; Darmanin, C.; Chung, R. P. Sorbitol dehydrogenase: structure, function and ligand design. Current Medicinal Chemistry,

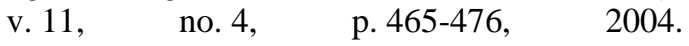
http://dx.doi.org/10.2174/0929867043455927

Estevinho, L.; Pereira, A.; Moreira, L.; Dias, L.; Pereira, E. Antioxidant and antimicrobial effects of phenolic compounds extracts of Northeast Portugal honey. Food and Chemical Toxicology, v. 46, no. 12, p. 3774-3779, 2008. http://dx.doi.org/10.1016/j.fct.2008.09.062

Igbokwe, V. U.; Gege-Adebayo, G. I.; Ogbadu, S. Pure honey a potent fertility booster: activities of honey on sperm parameters in young adult rats. IOSR Journal of Dental and Medical Sciences, v. 9, no. 6, p. 43-47, 2013. Available from: <http://www.iosrjournals.org/ iosr-jdms/papers/Vol9-issue6/G0964347.pdf? id=7024>. Accessed in: Apr. 23, 2016.

Mahaneem, M.; Sulaiman, S. A.; Jaafar, H.; Sirajudeen, K. N. S.; Ismail, Z. I. M.; Islam, N. M. Effect of honey on testicular functions in rats exposed to cigarette smoke. Journal of ApiProduct and ApiMedical Science, v. 3, no. 1, p. 12-17, 2011. Available from: <http://www.ibrabee.org.uk/component/content/ article?layout=edit\&id=3260>. Accessed in: Apr. 23, 2016.

Olayemi, F. O. A review on some causes of male infertility. African Journal of Biotechnology, v. 9, no. 20, p. 2834-2842, 2010. Available from: <http://www.ajol.info/ index.php/ajb/article/viewFile/79938/70206>.

Accessed in: Apr. 23, 2016.

Raji, Y.; Awobajo, F. O.; Kunle-Alabi, T.; Gbadegesin, M. A.; Bolarinwa, A. F. In vivo and in vitro reproductive toxicity assessment of ampicillin and cloxacillin in mammalian models. International Journal of Pharmacology, v. 2, no. 1, p. 9-14, 2006. http://dx.doi.org/10.3923/ijp.2006.9.14 
Raji, Y., Oloyo, A. K.; Morakinyo, A. O. Studies on the reproductive activities of methanol extract of Ricinus communis seed on male albino rats. Asian J. Androl., v. 8, no. 1, p. 115-121, 2006. http://dx.doi.org/10.1111/j.17457262.2006.00055.x

Shittu, L. A.; Izegbu, M. C.; Babalola, O. S.; Adesanya, O. A.; Ashiru, O. A. Penems and related substances. Phil. Trans. Royal Soc. Chem. B., v. 289, no. 1036, p. 239-250, 2005.

Sikka, S. C.; Wang, R. Endocrine disruptors and estrogenic effects on male reproductive axis. Asian Journal of Andrology, v. 10, p. S134S145, 2008. http://dx.doi.org/10.1111/j.17457262.2008.00370.x
Simmons, J. E.; Yang, R. S. H.; Berman, E. Evaluation of the nephrotoxicity of complex mixtures containing organics and metal: advantages and disadvantages of the use of realworld complex mixtures. Environmental Health Perspectives, v. 103, p. 67-71, 1995. Available from: <http://www.ncbi.nlm.nih.gov/ pmc/articles/PMC1519327/pdf/envhper003610070.pdf>. Accessed in: Apr. 23, 2016.

Syazana, N. S.; Hashida, N. H.; Majid, A. M.; Durriyyah, H. A.; Kamaruddin., M. Y. Effects of gelam honey on sperm quality and testis of rat. Sains Malaysiana, v. 40, n. 11 , p. 12431246, 2011. <http://journalarticle.ukm.my/ 2934>. Accessed in: Apr. 23, 2016. 